\title{
Tıp fakültesi öğrencilerinin meme kanseri ve kendi kendine meme muayenesi ile ilgili bilgi ve tutumlarının değerlendirilmesi
}

\author{
Evaluation of knowledge and attitudes of medical faculty students about breast \\ cancer and self breast examination
}

\author{
Sevda Yılmaz, Nilüfer Emre, Muhammed Raşid Aykota
}

\section{Özet}

Amaç: Meme kanseri Türkiye'de ve Dünya'da kadınlarda en sık tanı alan kanser türünü oluşturmaktadır. Bu çalışmanın amacı, Tıp Fakültesinde okuyan öğrencilerin meme kanseri ve kendi kendine meme muayenesi hakkında bilgi ve tutumlarının değerlendirilmesidir.

Gereç ve yöntem: Kesitsel tipteki bu çalışmaya, Pamukkale Üniversitesi Tıp Fakültesi öğrencileri dahil edildi. Çalışmaya katılan öğrencilere sosyo-demografik özellikleri içeren ve meme kanseri ve KKMM ile ilgili bilgi ve tutumdan oluşan 17 soruluk anket formu yüz yüze uygulandı. Veriler SPSS 22.0 (Statistical Package For Social Sciences) paket programıla analiz edildi.

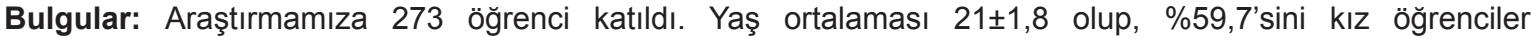
oluşturmaktaydı. Öğrencilerin \%10,6'sının ailesinde meme kanseri öyküsü mevcuttu. Öğrencilerin \%69,6'sı (n:190) kendi kendine meme muayenesi yapmayı bildiği ve \%42,9'unun kendi kendine meme muayenesi yaptığı tespit edildi. Meme kanserine neden olan en önemli risk faktörleri sorgulandığında; en sık verilen cevaplar: ailede meme kanseri öyküsünün olması $(\% 87,9)$, radyasyona maruziyet $(\% 86,8)$ ve yaşın artması $(\% 85,7)$ idi. Meme kanseri belirtileri sorgulandığında ise en sık verilen cevaplar; aksillada lenfadenopati varlığı $(\% 79,1)$ ve memede kitle olması $(\% 75,8)$ idi.

Sonuç: Kadınlarda meme kanseri erken tanısına yönelik tarama bilincinin arttırılması ve bu taramaların düzenli yapılması için, sağlık çalışanları ve adaylarına yönelik eğitim programlarının yapılandırıması ve uygulanması gerekmektedir.

Anahtar kelimeler: Kendi kendine meme muayenesi, meme kanseri, bilgi, tutum, öğrenci.

Yılmaz S, Emre N, Aykota MR. Tıp fakültesi öğrencilerinin meme kanseri ve kendi kendine meme muayenesi ile ilgili bilgi ve tutumlarının değerlendirilmesi. Pam Tıp Derg 2020;13:351-356.

\begin{abstract}
Abstrat
Purpose: Breast cancer is the most frequently diagnosed type of cancer among women in Turkey and the World. The aim of this study was to evaluate the knowledge and attitudes of the students of the Faculty of Medicine about breast cancer and breast self-examination.

Materials and method: The study is a cross sectional study, consisted of students who accepted to participate among medical faculty students in Pamukkale University. A 17-question questionnaire including sociodemographic characteristics and knowledge and attitudes about breast cancer and breast self-examination was administered to the students who participated in the study. Data were analyzed with SPSS 22.0 (Statistical Package for Social Sciences).

Results: 273 students participated in the study. The mean age was $21 \pm 1.8$ years and $59.7 \%$ of them were female students. $10.6 \%$ of the students had a family history of breast cancer. $69.6 \%(n: 190)$ of the students knew how to do breast self-examination and $42.9 \%$ were found to do breast self-examination. When breast cancer risk factors were questioned, most frequently answered were; family history of breast cancer $(87.9 \%)$, radiation exposure $(86.8 \%)$ and increase in age (\%85.7). When breast cancers symptoms were questioned, most frequently answered were; axillary lymphadenopathy $(79.1 \%)$ and breast mass $(75.8 \%)$.

Conclusion: Screening methods for health workers and candidates should be structured and implemented in order to increase awareness of early detection of breast cancer in women and to conduct these screenings regularly.
\end{abstract}

Key words: Breast self-examination, breast cancer, knowledge, attitude, student.

Yılmaz S, Emre N, Aykota MR. Evaluation of knowledge and attitudes of medical faculty students about breast cancer and self breast examination. Pam Med J 2020;13:351-356.

Sevda Yılmaz, Dr. Öğr. Üye. Pamukkale Üniversitesi Tıp Fakültesi Genel Cerrahi Anabilim, Denizli, Türkiye, e-posta: syilmaz_md@hotmail.com (orcid.org/0000-0002-1309-0805) (Sorumlu Yazar)

Nilüfer Emre, Dr. Öğr. Üye. Pamukkale Üniversitesi Tıp Fakültesi Aile Hekimliği Anabilim, Denizli, Türkiye, e-posta: nilemre83@gmail.com (orcid.org/0000-0002-6519-0920)

Muhammed Raşid Aykota, Dr. Öğr. Üye. Pamukkale Üniversitesi Tıp Fakültesi Genel Cerrahi Anabilim, Denizli, Türkiye, e-posta: muhammedaykota@hotmail.com (orcid.org/0000-0003-1862-6186) 


\section{Giriş}

Meme kanseri kadınlar arasında en sık görülen kanserdir ve her yıl 2,1 milyon kadını etkilemektedir. Dünya Sağlık Örgütü verilerine göre 2018 yılında, yeni tanı meme kanseri oranı \%11,6 olarak bildirilmiştir [1, 2]. Türkiye'de meme kanser insidansı 1993'de 24,1/100000, 2006'da 37,6/100000, 2008 41,6/100000 ve 2015 'de bu oran 43,8'e yükselmiştir. Ülkemizde yaş dağılımı açısından meme kanseri vakaları incelendiğinde, \%42,5'inin $15-49$ yaşları arasında olduğu, meme kanseri evreleri incelendiğinde ise invaziv vakaların sadece \%8,4'ünün uzak evrede olduğu gösterilmiştir [3].

Son bir yıl içinde Türkiye'de 17183 kadına meme kanseri teşhisi konulmuştur [3]. Bu nedenle toplumda meme kanseri farkındalığını arttırma çalışmaları ve tarama programları önem taşımaktadır. Meme kanseri tanılarının $\% 61 ' i$ tarama yöntemleri ile erken lokalize dönemde konularak, etkin tedavi ile iyi prognoz sağlanabilmektedir. Erken dönemde tanı alan hastalarda 5 yıllık sağ kalım beklentileri \%99'dur [4]. Tarama programlarının amacı meme kanseri gibi kadınlarda sık görülen bir kanserin erken dönemde tanısını koyarak, etkin tedavi yöntemleriyle hastaların sağkalım sürelerini uzatmak, yaşam kalitelerini yükseltmek ve meme koruyucu tedavi seçenekleri sunabilmektir. Meme kanseri tanısında erken tanı için önerilen üç yöntem vardır. Bu yöntemlerden ilki "Kendi Kendine Meme Muayenesi (KKMM)", ikincisi sağlık personeli tarafından yapılan "klinik meme muayenesi" ve üçüncüsü "mamografidir" [5]. Bizım bu çalışmamızın amacı; Pamukkale Üniversitesi Tıp Fakültesi öğrencilerinin meme kanseri farkındalığını arttırmak ve kendi kendine meme muayenesi hakkında bilgi ve tutumlarının değerlendirilmesidir.

\section{Gereç ve yöntem}

Kesitsel tipteki bu çalışma, Pamukkale Üniversitesi Tıp Fakültesinde 2019 Haziran ayında yapıldı. Araştırma öncesinde Pamukkale Üniversitesi Tıp Fakültesi girişimsel olmayan klinik araştırmalar etik kurulundan 11.06.2019 tarih ve 11 sayılı kurul kararıyla onay alındı. Araştırmanın evreni Pamukkale Üniversite Tıp Fakültesinde okuyan 1., 2., 3., 4. ve 5. sınıf $(n=1129)$ öğrencileri oluşturdu. Araştırmada örneklem seçimine gidilmeyip, tüm evrene ulaşıması hedeflendi. Araştırma yapılacağı tarihlerde izinli veya raporlu olan, araştırmayı kabul etmeyen öğrenciler çalışma dışı bırakıldı. Çalışmayı kabul eden öğrencilere, literatür taranarak oluşturulan meme kanseri ve KKMM ile ilgili bilgi ve tutumu içeren sorular ve sosyodemografik verilerden oluşan 17 soruluk anket formu uygulandı. Veriler SPSS 22.0 (Statistical Package For Social Sciences) paket programıla analiz edildi. Sürekli değişkenler ortalama \pm standart sapma ve kategorik değişkenler sayı ve yüzde olarak verildi. Kategorik değişkenler arasındaki farklılıklar ise $\mathrm{Ki}$ kare analizi ile incelendi.

\section{Bulgular}

Araştırmamıza 273 öğrenci katıldı. Öğrencilerin yaş ortalaması $21 \pm 1,8$ (18-27) idi. Çalışmaya katılanların \%59,7'si (n:163) kız öğrenci, \%98,9'u (n:270) bekardı. Öğrencilerin \%25,3'ü (n=69) tıp fakültesi 1. sınıf, \%30'u ( $n=82)$ 2.sınıf, \%15,8'i $(n=43) 3$. sınıf, \%16,8'i $(n=46)$ 4. sınıf, \%12,1'i $(n=33) 5$. sınıfta öğrenim görmekteydi. \%10,6'sının (n:29) ailesinde meme kanseri öyküsü mevcuttu. Öğrencilerin \%69,6'sı (n:190) KKMM yapmayı biliyordu ve bilenlerin $\% 39,2$ 'sinin (n:107) bu bilgiyi derslerden edindiği tespit edildi (Tablo 1). \%42,9'unun kendi kendine meme muayenesi yaptığı tespit edildi. Ailede meme kanseri öyküsü olan öğrencilerin \%55,2'sinin KKMM yaptı̆ı̆ bulundu ve ailede meme kanseri öyküsü olanlar ve olmayanlar arasında KKMM yapma açısından istatistiksel olarak anlamlı fark saptanmadı $(p=0,156)$. KKMM yapmayı bilme ile sınıf düzeyi arasında anlamlı ilişki bulunmadı $(p=0,259)$.

"Kadınlar hangi yaşta KKMM yapmaya başlamalı?" sorusuna \%37'si 20 yaşında şeklinde doğru cevap verdi. KKMM'nin yapılma sıklığı sorulduğunda \%47,6'sı (n:130) ayda bir şeklinde doğru cevap verirken, \%33,3'ü (n:91) herhangi bir zamanda yapılabilir şeklinde cevap verdi. KKMM yapılma zamanı sorusuna, \%30,4'ü (n:83) adet dönemi sonrasında olarak doğru cevap verdi (Tablo 2 ).

Meme kanserine neden olan risk faktörleri sorulduğunda; \%87,9'u (n: 240) ailede meme kanseri öyküsünün olması, \%86,8'i (n:237) radyasyona maruziyet ve \%85,7'si (n:234) artan yaşın en önemli risk faktörleri olduğunu belirtti (Tablo 3). Meme kanseri belirtileri sorulduğunda; $\% 79,1^{\prime} \mathrm{i}$ (n:216) aksillada lenfadenopati varlığı ve $\% 75,8$ 'i (n:207) memede kitle olarak cevapladı. 
Öğrenciler KKMM ile herhangi bir kitle ya da değişiklik fark ettiklerinde \%45,4'ü (n:124) ilk olarak aile hekimliğine başvuracaklarını belirtirken, \%36,6'sı (n:100) ise genel cerrahi polikliniğine başvuracağını belirtti.

Öğrencilerin $\quad \% 57,1 \quad(n: 156) \quad$ KKMM yapmadığını belirtirken, yapmayanların neden yapmadığı sorgulandığında \%17,9'u (n:49) nasıl yapıldığını bilmediğinden, \%16,5’i (n:45) ise şikayeti olmadığından yapmadığını belirtti (Tablo 4).

\section{Tartışma}

Meme kanseri tarama yöntemleri içinde en önemli yöntemlerden biri olan KKMM'nin bilinmesi ve uygulanmasına yönelik dünyada ve ülkemizde yapılan çalışmalarda farklı sonuçlar

Tablo 1. KKMM bilgi edinme kaynakları.

\begin{tabular}{lcc}
\hline & Sayı $(\mathbf{n}){ }^{*}$ & $\%$ \\
\hline Dersler & 107 & 39,2 \\
İnternet & 28 & 10,3 \\
Sağlık kuruluşları & 58 & 21,2 \\
Akraba/arkadaş & 23 & 8,4 \\
Afiş/dergi/broşür & 48 & 17,6 \\
Tv/radyo & 23 & 8,4 \\
\hline
\end{tabular}

*Birden fazla şık işaretlenmiştir.

KKMM: kendi kendine meme muayenesi

Tablo 2. KKMM uygun zamanı, yaş ve yapma sıklığı.

\begin{tabular}{lcc}
\hline & (n) & $\%$ \\
\hline KKMM yapma dönemi & & \\
Adet sonrası & 83 & 30,4 \\
Adet öncesi & 11 & 4,0 \\
Adet esnasında & 9 & 3,3 \\
Zaman farketmez & 91 & 33,3 \\
Bilmiyorum & 79 & 29 \\
Toplam & 273 & 100 \\
KKMM yapmaya başlama yaşı & & \\
20 yaşında & 104 & 38,1 \\
30 yaşında & 15 & 5,5 \\
40 yaşında & 14 & 5,1 \\
Her yaştaki kadın & 117 & 42,9 \\
Bilmiyorum & 23 & 8,4 \\
Toplam & 273 & 100 \\
KKMM yapma sıklığı & & \\
Haftada bir & 28 & 10,3 \\
Ayda bir & 130 & 47,6 \\
Altı ayda bir & 47 & 17,2 \\
Şikayeti oldukça & 9 & 3,3 \\
Bilmiyorum & 59 & 21,6 \\
Toplam & 273 & 100 \\
\hline
\end{tabular}

bildirilmiştir. Dünya'da yapılan çalışmalarda KKMM oranı \%10-44,2 aralığında bildirilmiştir $[6,7]$.

Türkiye'de meme kanseri eğitimine yönelik yapılan çalışmaların genellikle KKMM çalışmaları olduğu ve eğitimin davranış değişiminde etkili olduğu görülmektedir. Türkiye'de meme kanseri farkındalığı ile ilgili yapılan çalışmaların sonuçlarına göre; KKMM oranı \%10,2-84,1 aralığında bulunmuştur. KMMM'nin neden yapılmadığı sorulduğunda ise \%50-71 aralığında nasıl yapılacağı bilinmediği için yapılmadığı bildirilmiştir [8-20]. Bizim çalışmamızda da öğrencilerin KKMM yapma oranları \%42,9 olarak bulunmuştur. KKMM bilgisinin nereden edinildiği literatürde yapılan araştırmalarda, çalışma grubuna göre değişiklik göstermektedir. Sağlık kuruluşuna 
Tablo 3. Öğrencilerin meme kanseri risk faktörlerini bilme durumları.

\begin{tabular}{|c|c|c|c|c|c|c|}
\hline & \multicolumn{2}{|r|}{ Evet } & \multicolumn{2}{|r|}{ Hayır } & \multicolumn{2}{|c|}{ Bilmiyorum } \\
\hline & $\mathbf{n}$ & $\%$ & $\mathbf{n}$ & $\%$ & $\mathbf{n}$ & $\%$ \\
\hline Yaş & 234 & 85,7 & 10 & 3,7 & 29 & 10,6 \\
\hline İlk doğumunu erken yaşlarda yapanlarda & 92 & 33,7 & 62 & 22,7 & 119 & 43,6 \\
\hline Menopoza 55 yaşından sonra girenlerde & 146 & 53,5 & 34 & 12,5 & 93 & 34,1 \\
\hline Erken(12 yaşından küçük) yaşta adet görenlerde & 133 & 48,7 & 34 & 12,5 & 106 & 38,8 \\
\hline Ailesinde meme kanseri olanlarda artar & 240 & 87,9 & 4 & 1,5 & 29 & 10,6 \\
\hline Doymuş yağla beslenenlerde artar & 153 & 56,0 & 15 & 5,5 & 105 & 38,5 \\
\hline Doğum kontrol hapı kullananlarda artar & 136 & 49,8 & 30 & 11 & 107 & 39,2 \\
\hline Emzirmeyen kadınlarda artar & 41 & 15,0 & 115 & 42,1 & 117 & 42,9 \\
\hline Alkol ve sigara kullanan kadınlarda artar & 203 & 74,4 & 9 & 3,3 & 61 & 22,3 \\
\hline Radyasyona maruz kalanlarda artar & 237 & 86,8 & 2 & 0,7 & 34 & 12,5 \\
\hline
\end{tabular}

*Birden fazla şık işaretlenmiştir.

Tablo 4. Meme kanseri belirtilerini bilme oranları.

\begin{tabular}{lcccccc}
\hline & \multicolumn{2}{c}{ Evet } & \multicolumn{2}{c}{ Hayır } & \multicolumn{2}{c}{ Bilmiyorum } \\
& $\mathbf{n}$ & $\mathbf{\%}$ & $\mathbf{n}$ & $\%$ & $\mathbf{n}$ & $\%$ \\
\hline Meme ucundan kanlı akıntı gelmesi & 156 & 57,1 & 18 & 6,6 & 99 & 36,3 \\
Memede asimetri & 135 & 49,5 & 69 & 25,3 & 69 & 25,3 \\
Memede kitle olması & 207 & 75,8 & 22 & 8,1 & 44 & 16,1 \\
Meme renginde değişiklik & 166 & 60,8 & 24 & 8,8 & 83 & 30,4 \\
Lenf nodu büyümesi & 216 & 79,1 & 10 & 3,7 & 47 & 17,2 \\
Memede çukurlaşma & 153 & 56 & 19 & 7 & 101 & 37 \\
Memede anormal sarkma & 121 & 44,3 & 48 & 17,6 & 104 & 38,1 \\
Meme cildinde portakal kabuğu görünümü & 102 & 37,4 & 60 & 22 & 111 & 40,7 \\
Meme cildinde çekinti & 135 & 49,5 & 29 & 10,6 & 109 & 39,9 \\
\hline
\end{tabular}

*Birden fazla şık işaretlenmiştir.

başvuranlarda yapılan çalışmalarda ve sağlık eğitimi alan öğrencilerde sağlık personelinden ve televizyon/gazete bilgi edinme ilk sıralarda yer alırken bizim çalışmamızda derslerden ve sağlık kuruluşlarında bilgi edinme benzer şekilde ilk sıralarda yer almaktadır [21, 22].

Kadınların KKMM yapmaktaki isteksizliklerinin, bir kitle bulma ve bu durumda ne yapacağını bilememe korkusu ile ilişkili olduğu, meme muayenesi hakkındaki bilgilerinin yeterli olmadığı ve bu durumun eğitimle azaltılabileceği Koç ve Sağlam [21] tarafından bildirilmektedir. Benzer şekilde, Aydoğdu ve Karapelit [23] çalışmasında öğrencilerin KKMM yapmama nedenlerini; meme muayenesini bilmemeleri, meme kanseri için risk taşımadıklarını düşünmeleri, kötü bir sonuç alma endişesi, zamanlarının olmaması veya unutmaları olarak bildirilmiştir. Bizim çalışmamızda ise öğrencilerin \%30,4'ünün KKMM yapmayı bilmediği ve $\% 16,5$ ' $\mathrm{i}$ ise şikayeti olmadığı için yapmadıklarını bildirmişlerdir.

Aydoğdu ve Karapelit'in [23] çalışmalarında öğrencilerin öğrenim gördükleri sınıflara göre KKMM yapma durumları incelendiğinde, sınıf düzeyine paralel olarak KKMM yapma oranlarının yükseldiği görülmüştür. Gündoğan ve arkadaşları [24] ise, üst sınıflarda alt sınıflara kıyasla güven/öz-etkinlik oranlarının arttığını, bunun KKMM'ye olan yarar algısı ve uygulamasına eğilimi etkilediğini saptamışlardır. Bizim çalışmamızda KKMM yapmayı bilme 
oranları sınıf düzeyi arttıkça artarken, yapma oranları ile sınıf düzeyi karşılaştırıldığında anlamlı ilişki saptanmadı.

Amerikan Kanser Birliği, 20 yaşından itibaren tüm asemptomatik kadınların her ay düzenli olarak KKMM yapmasını önermektedir. KKMM için en uygun zaman, adet kanamasından beş ila yedi gün sonra, memelerin hassas ve gergin olmadığı zamandır [25]. İstanbul ilinde çalışan doktor ve hemşirelerin KKMM'ne yönelik uygulama ve tutumlarının incelendiği bir çalışmada hemşirelerin \%41'inin, doktorların \%38'inin KKMM'ni doğru zamanda yapmadıkları belirlenmiştir [26]. Üniversite öğrencilerinde yapılan bir çalışmada da \%54'ü adet sonrası KKMM yaptığını belirtmiştir [27]. Aydoğdu ve Karapelit'in [22] ebelik öğrencilerinde yaptıkları çalışmalarında KKMM'e hangi yaşta başlanacağı ve adet gören kadında ne zaman yapılacağı ile ilgili olan sorulara çoğunlukla yanlış yanıt verdikleri görülmüş ve bu durumun sebebi olarak alt sınıftaki öğrencilerin KKMM hakkındaki bilgi yetersizlikleri gösterilmiştir. Bizim çalışmamızda ise öğrencilerin \%30,4'ü adet sonrası dönemde KKMM'nin yapılması gerektiğini ve \%37'si de 20 yaşından itibaren KKMM yapılması gerektiğini belirtmiştir.

Alan ve ark.'nın [27] çalışmasında meme kanserinde en sık görülen bulgular ile ilgili olarak verilen yanıtlar arasında memede kitle, aynı taraflı koltuk altı lenf bezlerinde şişme, memenin anormal büyümesi ve memenin asimetrik büyümesi en sık bulgu olarak saptanmıştır. Şen ve Başar'ın [28] çalışmasında meme başından akıntı, memede ağrı, memede ve koltuk altında ele gelen şişlik en sık görülen belirtilerdir. Parlar ve ark. [11] ise yapmış olduğu çalışmada kadınların meme kanseri belirtisi olarak kitle, memede büyüme, kanlı akıntı, memede çukurlaşmayı ilk sıralarda ifade ettiklerini saptamışlardır. Bizim çalışmamızda da diğer çalışmalarla benzer şekilde öğrencilerin büyük çoğunluğu meme kanseri belirtileri olarak en sık memede kitle ve aksillada lenfadenopati varlığı olduğunu belirtmişlerdir. Meme kanseri belirti ve bulgularının yanı sıra meme kanseri risk faktörleri ile ilgili sorulara da birinci sırada aile hikayesi, ikinci sırada radyasyon maruziyeti ve üçüncü sırada yaş faktörünü belirten öğrencilerin bu konuda yeterli bilgi düzeyine sahip oldukları aşikardır.
Tıp Fakültesi öğrencilerinde yapılan bu çalışmada öğrencilerin meme kanseri belirti ve risk faktörleri, KKMM yapma ile ilgili yeterli bilgi düzeyine sahip oldukları ancak KKMM yapmadıkları görülmüştür.

Çalışmamızdaki kısıtılıklar, araştırmaya katılan öğrenci sayısının az olması ve yapılan çalışmanın sadece uygulama yapılan gruba genellenebilmesidir.

Kadınlarda meme kanseri erken tarama yöntemlerinden biri olan KKMM'nin yeterli uygulanmadığını gösteren bu çalışmalar ve çalışmamızın sonuçlarına göre; KKMM'ye yönelik bilincin arttırılması ve düzenli olarak yapılması için sağlık çalışanları ve adayları için eğitim programlarının yapılandırılması ve uygulanması gerektiğini ortaya koymaktadır.

Çıkar ilişkisi: Yazarlar çıkar çatışması olmadığını bildirmişlerdir.

\section{Kaynaklar}

1. Bray F, Ferlay J, Soerjomataram I, Siegel RL, Torre LA, Jemal A. Global cancer statistics 2018: GLOBOCAN estimates of incidence and mortality worldwide for 36 cancers in 185 countries. CA Cancer J Clin 2018;68:394-424. https://doi.org/10.3322/caac.21492

2. Breast cancer. WHO Available at: http://www.who.int/ cancer/prevention/diagnosis-screening/breast-cancer/ en. Accessed 21 Aralık 2019

3. Turkiye_Kanser_Istatistikleri_2015.pdf. Erişim adresi: https://hsgm.saglik.gov.tr/depo/birimler/kanser-db/ istatistik/Turkiye_Kanser_Istatistikleri_2015.pdf. Erişim tarihi 21 Aralık 2019

4. Cancer Facts and Figures 2014. American Cancer Society Available at: http://www.cancer.org/acs/ groups/content/@research/documents/webcontent/ acspc-042151.pdf. Accessed December 21, 2019

5. Cardoso F, Kyriakides S, Ohno S, et al. Early breast cancer: ESMO clinical practice guidelines for diagnosis, treatment and follow-up. Ann Oncol 2019;30:11941220. https://doi.org/10.1093/annonc/mdz173

6. Segni MT, Tadesse DM, Amdemichael R, Demissie HF. Breast self-examination: knowledge, attitude and practice among female health science students at Adama Science and Technology University, Ethiopia. Gynecol Obstet (Sunnyvale) 2016;6:368. https://doi. org/10.4172/2161-0932.1000368

7. Sapountzi-Krepia D, Releiti M, Lavdaniti $M$, et al. Evaluating female nursing students' knowledge and attitudes regarding breast self-examination. Health Care Women Int 2017;38:786-795. https://doi.org/10.1 080/07399332.2017.1326921 
8. Beydağ KD, Karaoğlan H. Kendi kendine meme muayenesi eğitiminin öğrencilerin bilgi ve tutumlarına etkisi. TSK Koruyucu Hekimlik Bülteni 2007;6:106-111.

9. Alpteker H, Gümüş $D$, Doğan $S$, Bilir $S$, Önal M. Kız öğrencilerīn meme kanserĩ ve kendï kendine meme muayenesĩ billgì ve uygulamalarının incelenmesĩ. Meme Sağlığı Dergisi/Journal of Breast Health 2011;7.

10. Özer A, Bankaoğlu E, Ekerbiçer HÇ, Hüdayioğlu MR, Özdemir M. Kahramanmaraş'ta yaşayan bir grup kadının kendi kendine meme muayenesi yapma ve mammografi çektirme durumu ile bunları etkileyen faktörler. 2009;28:14-19.

11. Parlar S, Bozkurt Al, Ovayolu N. Bir ana çocuk sağı̆ğı merkezine başvuran kadınlara verilen meme kanseri ve kendi kendine meme muayenesi ile ilgili eğitimin değerlendirilmesi. Cumhuriyet Üniversitesi Hemşirelik Yüksekokulu Dergisi 2004;8:9-15.

12. Güner IC, Tetik A, Gönener HD. Kadınların kendi kendine meme muayenesi (KKMM) ile ilgili bilgi, tutum ve davranışlarının belirlenmesi. Gaziantep Tıp Dergisi 2007; 13:55-60.

13. Aslan A, Temiz M, Yiğit Y, Can R, Canbolant, E, Yiğit F. Hemşirelik Yüksek Okulu öğrencilerinin meme kanseri hakkında bilgi, tutum ve davranışları. TSK Koruyucu Hekimlik Bülteni 2007;6:193-198.

14. Dişcigil G, Şensoy N, Tekin N, Söylemez A. Meme Sağlığı: Ege bölgesinde yaşayan bir grup kadının bilgi, davranış ve uygulamaları. Marmara Med J 2007;20:2936.

15. Yılmazel G. Çorum ili kırsalında yaşayan 20 yaş ve üzerindeki kadınların kendi kendine meme muayenesi yapma durumları ve meme kanseri risk faktörlerinin belirlenmesi. J Breast Health 2013;9:82-87. Available at: https://www.researchgate.net/publication/255988565. Accessed January 28, 2013

16. Dündar PE, Ozmen D, Oztürk B, et al. The knowledge and attitudes of breast self-examination and mammography in a group of women in a rural area in western Turkey. BMC Cancer 2006;6:43. https://doi. org/10.1186/1471-2407-6-43

17. Demir Yıldırım A, Özaydın AN. Sources of breast cancer knowledge of women living in Moda/istanbul and their attendance to breast cancer screening. J Breast Health 2014;10:47-56. https://doi.org/10.5152/tjbh.2014.1762

18. Akkuş $Y$, Çiçek E, Şahan S, Ülger F. Bir kız yurdunda kalan üniversite öğrencilerinin kendi kendine meme muayenesi (KKMM) konusunda bilgi ve uygulamaları. IV Ulusal Hemşire Öğrencileri Kongresi Bildiri Özet Kitabı 2005;47.

19. Aygın D, Uludağ $C$, Şahin $S$. Gençlerin meme kanseri ve kendi kendine meme muayenesi hakkındaki bilgi, tutum ve davranışlarının değerlendirilmesi. Hemşirelik Forumu 2004;7:1-6.
20. Aydın İ. Üniversite öğrencilerinin kendi kendine meme muayenesi hakkındaki bilgileri ve uygulamaları. Anadolu Hemşirelik ve Sağlık Bilimleri Dergisi Hemşirelik Yüksekokulu Dergisi 2004;7.

21. Koç Z, Sağlam Z. Kadınların meme kanseri, koruyucu önlemler ve kendi kendine meme muayenesi ile ilgili bilgi ve uygulamalarının belirlenmesi ve eğitimin etkinliği. J Breast Health 2009;5:25-33.

22. Göçgeldi $\mathrm{E}$, Açıkel $\mathrm{CH}$, Hasde $\mathrm{M}$, et al. AnkaraGölbaşı ilçesinde bir grup kadının kendi kendine meme muayenesi yapma konusundaki tutum ve davranışlarının belirlenmesi. Fırat Tıp Dergisi 2008;13:261-265.

23. Aydoğdu SGM, Karapelit Z. Ebelik öğrencilerinin kendi kendine meme muayenesi ile ilgili bilgi ve tutumlarının belirlenmesi. Androl Bul 2017;19:78-85. https://doi. org/10.24898/tandro.2017.39200

24. Gündoğan D, Akın S, Durna Z, Şirin A. Hemşirelik öğrencilerinin kendi kendine meme muayenesine ilişkin tutum ve inançlarının değerlendirilmesi. Sağlık ve Toplum 2012;22:23-37

25. American Cancer Society. Breast Cancer Early Detection. Available at: http://www.cancer.org/Cancer/ BreastCancer. Accessed December 12, 2019

26. Çavdar Y, Akyolcu N, Özbas A, Öztekin D, Ayoğlu T, Akyüz N. Determining female physicians' and nurses' practices and attitudes toward breast self-examination in Istanbul, Turkey. Oncol Nurs Forum 2007;34:12181221. https://doi.org/10.1188/07.ONF.1218-1221

27. Alan H, Karadağıı F, Şıpkın S, Kocadaş S. Yurtta kalan üniversite öğrencilerinin meme kanseri ve kendi kendine meme muayenesi uygulama durumları. Haydarpaşa Numune Eğitim ve Araştırma Hastanesi Tıp Dergisi 2016;56:13-22.

28. Şen $S$, Başar F. Kütahya bölgesinde yaşayan kadınların kendi kendine meme muayenesi ve meme kanseri ile ilgili bilgi düzeyleri. Meme Sağlığı Dergisi 2012;8:185190

Teşekkür: Katkılarından dolayı İsmail Arda Tufan, Mustafa Gökçeoğlu, Tugay İçli, Zeynep Çivril'e teşekkür ederiz.

Etik onayı: Pamukkale Üniversitesi Tıp Fakültesi Girişimsel Olmayan Klinik Araştırmalar Etik Kurulu'ndan 11.06.2019 tarih ve 11 sayılı kurul kararıyla onay alınmıştır. 